\title{
Cooperative Regulation of Substrate Stiffness and Extracellular Matrix Proteins in Skin Wound Healing of Axolotls
}

\author{
Ting-Yu Huang, ${ }^{1}$ Cheng-Han Wu, ${ }^{2}$ Mu-Hui Wang, ${ }^{2}$ Bo-Sung Chen, ${ }^{3}$ \\ Ling-Ling Chiou, ${ }^{1}$ and Hsuan-Shu Lee ${ }^{2,3,4}$ \\ ${ }^{1}$ Liver Disease Prevention and Treatment Research Foundation, Taipei 10002, Taiwan \\ ${ }^{2}$ Institute of Biotechnology, College of Bioresources and Agriculture, National Taiwan University, Taipei 10617, Taiwan \\ ${ }^{3}$ Department of Internal Medicine, National Taiwan University Hospital and National Taiwan University College of Medicine, \\ Taipei 10002, Taiwan \\ ${ }^{4}$ Agricultural Biotechnology Research Center, Academia Sinica, Taipei 11529, Taiwan
}

Correspondence should be addressed to Hsuan-Shu Lee; benlee@ntu.edu.tw

Received 9 December 2014; Revised 22 February 2015; Accepted 24 February 2015

Academic Editor: Paul J. Higgins

Copyright (C) 2015 Ting-Yu Huang et al. This is an open access article distributed under the Creative Commons Attribution License, which permits unrestricted use, distribution, and reproduction in any medium, provided the original work is properly cited.

Urodele amphibians (Ambystoma mexicanum), unique among vertebrates, can regenerate appendages and other body parts entirely and functionally through a scar-free healing process. The wound epithelium covering the amputated or damaged site forms early and is essential for initiating the subsequent regenerative steps. However, the molecular mechanism through which the wound reepithelializes during regeneration remains unclear. In this study, we developed an in vitro culture system that mimics an in vivo wound healing process; the biomechanical properties in the system were precisely defined and manipulated. Skin explants that were cultured on 2 to $50 \mathrm{kPa}$ collagen-coated substrates rapidly reepithelialized within 10 to $15 \mathrm{~h}$; however, in harder (1 GPa) and other extracellular matrices (tenascin-, fibronectin-, and laminin-coated environments), the wound epithelium moved slowly. Furthermore, the reepithelialization rate of skin explants from metamorphic axolotls cultured on a polystyrene plate $(1 \mathrm{GPa})$ increased substantially. These findings afford new insights and can facilitate investigating wound epithelium formation during early regeneration using biochemical and mechanical techniques.

\section{Introduction}

Urodele amphibians (such as axolotls: Ambystoma mexicanum), unique among vertebrates, can regenerate appendages (tails and limbs) and other body parts (heart, spinal cord, lenses, and joints) entirely and functionally. The regeneration process in axolotls typically involves the following steps: (1) epithelial cells migrate from the cut edge and the wound epithelium forms, covering the amputated or damaged sites $[1,2]$; (2) blastema is generated, containing undifferentiated and proliferating mesenchymal cells $[3,4]$; and (3) in the later stage of regeneration, the blastema cells begin to redifferentiate and regrow in the original tissues and organs. The initiation of wound epithelium formation is crucial; however, various factors can hinder the regeneration process. For example, suturing a piece of skin on the wounded site immediately after amputation inhibits regrowth [5]. Unlike axolotls, mammals cannot regenerate most damaged organs and tissues, typically forming scars during the healing process instead; however, wound repair in fetal mammals and marsupials is scar-free [6-9]. Furthermore, the molecular and cellular developmental mechanisms of appendages and organs in vertebrates are similar and highly conserved to urodele amphibians. Therefore, it has been suggested that mammals can regenerate if particular factors or pathways activate downstream developmental signaling cascades [10]. Hence, comparing and investigating the differences in the early stages of wound healing between axolotls and mammals should enable insights into scar or scar-free wound healing in vertebrates and salamanders.

In axolotls and newts, the reepithelialization of wounded sites proceeds rapidly. Epidermal cells around the wound 
react and quickly migrate through pseudopodial projection $[5,11]$. The expression of $\beta 1$-integrin in the keratinocytes has been shown to support rapid migration on the wound bed [12]. Typically, the wounded site on juvenile axolotls can recover within $10 \mathrm{~h}$ [13] and even within $2 \mathrm{~h}$ on small axolotls $[14,15]$. Unlike the rapid recovery in axolotls, the healing of a similarly sized wound in mammals takes 2 to $3 \mathrm{~d}[16,17]$. This delayed reepithelialization in vertebrates is similar to the early phase of wound healing in metamorphic axolotls that requires $72 \mathrm{~h}$ for the wounded area to be recovered [1]. In amphibians, the metamorphosis from a larva to a juvenile indicates the transformation of the physiological system. Axolotls are generally neotenic and do not undergo full metamorphosis into adulthood. Nonetheless, adding thyroxine in the rearing water [18] or administering a single shot through intraperitoneal (ip) injection induces metamorphosis [19]. The epidermal transformation from a pseudostratified to a stratified state following metamorphosis is assumed to impede the reepithelialization occurring in response to injury [1]. Moreover, increasing amounts of evidence have shown that changes in biomechanical environments determine cell fate and development [20-22]. In newts, the transition of extracellular matrices at various stages of limb regeneration leads muscle cells to proliferation, migration, fragmentation, and fusion. In addition, substrates with a softer and tenascin-C-coated environment increase the migration and fragmentation of the primary newt muscle cells; however, environments with a stiffer and laminin- and fibronectincoated environment enhance cell differentiation [23].

In this research, we used an in vitro approach to investigate the early phase of an in vivo wound healing process in axolotls and the biomechanical properties in the system, including coated substances and degrees of substrate stiffness, both of which can be precisely defined and manipulated. Skin explants from the hind limbs of axolotls cultured on collagencoated substrates ranging from 2 to $50 \mathrm{kPa}$ rapidly reepithelialized within 10 to $15 \mathrm{~h}$; however in harder $(1 \mathrm{GPa})$ and other extracellular matrices (tenascin-, fibronectin-, and laminincoated environments), the wound area recovered slowly. The reepithelialization rate of metamorphic axolotl skin explants cultured on a polystyrene plate $(1 \mathrm{GPa})$ increased markedly. This advanced $2 \mathrm{D}$ culture system facilitates investigating the biochemical and mechanical mechanisms of wound epithelium formation during early regeneration in axolotls.

\section{Materials and Methods}

\subsection{Animal Care}

2.1.1. Axolotl Rearing. Axolotls (Ambystoma mexicanum), kept in a continuous-flow aquaria system in separate cages, were subjected to $12 \mathrm{~h}$ light- $12 \mathrm{~h}$ dark cycles; the temperature of the water ranged between $18^{\circ} \mathrm{C}$ and $20^{\circ} \mathrm{C}$. The water was UV-treated and biofiltered to prevent contamination with microorganisms. The environment consisting of circulating water with a pH value of 7.7 to 8.0 and a conductivity of 500 to $750 \mu \mathrm{S} / \mathrm{cm}$ was suitable for axolotl rearing. The axolotl larvae $(<5 \mathrm{~cm})$ were fed daily with brine shrimp (Artemia). The adult and juvenile axolotls $(6-20 \mathrm{~cm})$ were fed with fish pellets three times per week; leftovers were removed a few hours after feeding. The animals were anesthetized in a solution containing $0.1 \%$ MS222 (Sigma-Aldrich) before surgical procedures. Animal care and experimental procedures were approved by the Institutional Animal Care and Use Committee of the National Taiwan University College of Medicine.

2.1.2. Axolotl Metamorphosis. Axolotls are generally neotenic and reach adulthood without undergoing metamorphosis. However, we were able to induce metamorphosis using thyroxine $\left(\mathrm{T}_{4}\right)$, which was added to their rearing water [18] or administered through ip injection [19]. We intraperitoneally injected $1.5 \mu \mathrm{g}$ of $\mathrm{T}_{4} / \mathrm{g}$ (axolotl body weight) in juvenile axolotls $(10-12 \mathrm{~cm})$. Within 10 to $12 \mathrm{~d}$, the axolotls underwent complete metamorphosis.

\subsection{In Vitro Skin Culture}

2.2.1. Skin Explants Preparation. The skin explants were prepared in a culture hood. After the hind limbs of the axolotls were amputated, the full-thickness skin (including dermis and epidermis) covering the hind limbs was carefully removed with fine forceps and scissors and rinsed as follows: the skin was rinsed with $70 \%$ ethanol for $10 \mathrm{~s}$ and then with amphibian phosphate buffered saline (APBS: 60\% 1x PBS) three times for $30 \mathrm{~s}$ per rinse. The skins were cut into $4 \times 4 \mathrm{~mm}$ pieces in an APBS buffer, and a $2 \mathrm{~mm}$ hole was created in the center of the skin explants using a sterile biopsy punch (Miltex). Subsequently, the explants were transferred to 12 well culture plates featuring various biomechanical environments, and a $100 \mu \mathrm{L}$ culture medium (60\% Dulbecco's Modified Eagle Medium; 10\% fetal bovine serum; $1 \mathrm{x}$ Pen/Strep and ITS; $10 \mu \mathrm{g} / \mathrm{mL}$ of insulin, bovine pancreas; $5.5 \mu \mathrm{g} / \mathrm{mL}$ of human transferring; and $5 \mathrm{ng} / \mathrm{mL}$ of sodium selenite; Sigma-Aldrich) was applied to the center of the hollowed explants to retain moisture. After incubation at $22^{\circ} \mathrm{C}$ in an atmosphere with $1 \% \mathrm{CO}_{2}$ and $99 \%$ air for 2 to $3 \mathrm{~h}$, $200 \mu \mathrm{L}$ of additional culture medium was added to the wells. The samples were then ready for further observation using a real-time recording microscopy system.

2.2.2. Generation of Biomechanical Environments. We used hydrogels with four levels of stiffness $(0.2,2,12$, and $50 \mathrm{kPa}$, Matrigen, Brea, CA). The wells were coated with different substrates, such as tenascin $\left(2 \mu \mathrm{g} / \mathrm{cm}^{2}\right.$; Millipore CC065), fibronectin $\left(2 \mu \mathrm{g} / \mathrm{cm}^{2}\right.$; Millipore FC010), laminin $\left(2 \mu \mathrm{g} / \mathrm{cm}^{2}\right.$; Millipore CC095), and collagen type I rat tail $\left(20 \mu \mathrm{g} / \mathrm{cm}^{2}\right.$; 354236, BD Biosciences, Bedford, MA, USA), and diluted in PBS (1x) at $37^{\circ} \mathrm{C}$. After $\geq 1 \mathrm{~h}$ of incubation, the wells were gently rinsed three times with PBS (1x) to remove excess substrates and stored at $4^{\circ} \mathrm{C}$. Before the skin explants were transferred, the wells were rinsed with a culture medium three times for $30 \mathrm{~min}$ to rebalance the substrate. Two concentrations of collagen type I $\left(20 \mu \mathrm{g} / \mathrm{cm}^{2}\right.$ and $\left.300 \mu \mathrm{g} / \mathrm{cm}^{2}\right)$ were coated onto the polystyrene plate (24 wells, 3524, Corning Life Science) that exhibited a 1 GPa stiffness. 
2.3. Time-Lapse Microscopy for In Vitro Analysis. To monitor and record the entire process of wound closure in the skin explants, time-lapse microscopy was used. The plates with cultured skin explants were placed on a Laser TIRF 3 (Carl Zeiss) with high-resolution CCD (AxioCam MRm $1388 * 1040 \mathrm{P})$, and images were taken at $5 \mathrm{x}$ magnification every $15 \mathrm{~min}$ for $15 \mathrm{~h}$ in $x$-, $y$-, and $z$ - axes. Images were analyzed using AxioVision software and exported as AVI or TIFF files. The reepithelialization area was evaluated periodically using ImageJ software.

\section{Results}

\subsection{Analysis of Skin Explants in Biomechanical Environments}

3.1.1. Skin Explants on Soft Tissue-Like Substrate. Recent studies have indicated that cell development or differentiation responds to changes in the stiffness of the microenvironment [22, 24-26]. To investigate the mechanism regulating rapid wound closure in axolotls, we recorded the reepithelialization process of skin explants cultured on various collagen-coated substrates with varying degrees of stiffness ranging from 2 to $50 \mathrm{kPa}$ (Figure 1), which were similar to the stiffness of various organs, such as skeletal muscles, arteries, and skin [22]. The keratinocytes near the wound bed migrated little during a period of 1-2 h (Figures 1(a)-1(f); Figures 2(a)-2(c)). The average migration rate of keratinocytes ranged between 0.18 and $0.4 \mathrm{~mm}^{2} / \mathrm{h}$, and there was no significant difference of the average migration rates of these skin explants cultured on various degrees of substrate stiffness with collagen-coated wells (Figure 2(d)). Once most of the keratinocytes began to migrate, they typically did so at a consistent migration rate. However, we noticed an abruptly increase in the migration rate in few skin explants during the period of 6-10 h (Figure 2(a), filled circle; Figure 2(b), filled diamond). The wound-closure time in the cultured skins typically lasted $12 \mathrm{~h}$ and was comparable to the wound healing in vivo with a $1.5 \mathrm{~mm}$ punch [2] and a $4 \mathrm{~mm}$ punch [1], and the wound healing in an ex vivo culture with a $2 \mathrm{~mm}$ punch [27]; the recovery time of each wound lasted approximately 8, 24, and $11 \mathrm{~h}$, respectively. Increasing the size of the wound area twofold approximately doubled the healing time.

3.1.2. Skin Explants on Hard Tissue-Like Substrate. With the substrate stiffness from $2-50 \mathrm{kPa}$, the average migration rate of skin explants showed no significant difference (Figure 2(d)). To test the ability of the skin to recover in a harder environment, skin explants were cultured directly on a 20 and $300 \mu \mathrm{g} / \mathrm{cm}^{2}$ collagen-coated polystyrene plate. The former substrate featuring a stiffness of $1 \mathrm{GPa}$, which was approximately six orders of magnitude stiffer than the latter with stiffness of $1 \mathrm{kPa}$ [28]. In a hard environment, keratinocytes migrated little in the initial $12 \mathrm{~h}$ (Figures 3(e) and 3(f)), whereas they were almost covered around the wounded area in a culture exhibiting a softer environment (Figure 3(c)). Between 12 and $24 \mathrm{~h}$, the keratinocytes began to migrate slowly from the wound edge (Figures $3(\mathrm{f})$ and $3(\mathrm{~g})$ ) and already recovered completely in soft environment (Figure $3(\mathrm{~d})$ ). Comparing the average migration rate of the wound epithelium cultured on hard and soft environments showed significant difference after $6 \mathrm{~h}$ incubation (Figure 3(i)).

\subsubsection{Skin Explants in Extracellular Matrices-Coated Environ-} ments. To test whether the degree of stiffness and extracellular matrix proteins combined integrated signals to involve in the migration of epithelial cells, the three additional extracellular matrix proteins, tenascin, fibronectin, and laminin, were incorporated on soft substrate to culture skin explants. On substrate coated with tenascin and laminin, the skin explants scarcely covered the wounded area, and only partial reepithelialization occurred on the fibronectin-coated substrate (Table 1). Regarding the substrate coated with collagen, the softest substrate $(0.2 \mathrm{kPa}$ stiffness $)$ exhibited only partial recovery. Skin explants cultured on substrate featuring $2 \mathrm{kPa}$ stiffness exhibited the highest degree of full recovery $(83.3 \%$; $n=5$ in 6) compared with other substrates featuring stiffness of $12 \mathrm{kPa}(33.3 \% ; n=2$ in 6$)$ and $50 \mathrm{kPa}(50 \% ; n=3$ in 6$)$ (Table 1).

3.2. Analysis of Skin Explants from Metamorphic Axolotls. The reepithelialization in the initial phase of wound healing in metamorphic axolotls was complete within $72 \mathrm{~h}$, and the compositions and microenvironments near the epithelium presumably changed because of the metamorphosis [1]. To investigate whether the collagen-coated and substrate stiffness regulated the wound-epithelium recovery in metamorphic axolotls, we cultured skin explants on a polystyrene plate coated with two concentrations of collagen: 20 (1 GPa stiffness) and $300\left(1 \mathrm{kPa}\right.$ stiffness) $\mu \mathrm{g} / \mathrm{cm}^{2}$. The skin explants cultured for $24 \mathrm{~h}$ with $300 \mu \mathrm{g} / \mathrm{cm}^{2}$ of collagen exhibited minimal wound epithelium migration near the wound edge (Figures 4(b) and 4(c), arrows). By contrast, in the skin explants cultured with $20 \mu \mathrm{g} / \mathrm{cm}^{2}$ of collagen, the epithelium recovered most of the wound area (Figure 4(e), hollow arrowheads). The epithelial cells had moved inside, filling the wound area, and also progressed to the outside of the skin explants (Figure 4(f), hollow arrowheads). In addition, the average migration rate of the metamorphic wound epithelium was shown to be significantly different on hard and soft environments after $24 \mathrm{~h}$ culture (Figure $4(\mathrm{~g})$ ).

\section{Discussion and Conclusion}

In mammals, wound healing is a natural self-defense process that prevents microorganisms from intruding an open wound and leads to the formation of a collagenous scar at the wounded site [29]. Although wound closure is essential for maintaining tissue integrity, scars impair movement and can impede the function of some tissues and organs [30]. Unlike mammals, axolotls are capable of scar-free healing. The rapid onset and activation of keratinocyte migration within the first few hours of the initial phase of wound healing have been suggested to cause rapid reepithelialization in axolotls that is typically fivefold to tenfold faster than that in vertebrates 
$2 \mathrm{kPa}$

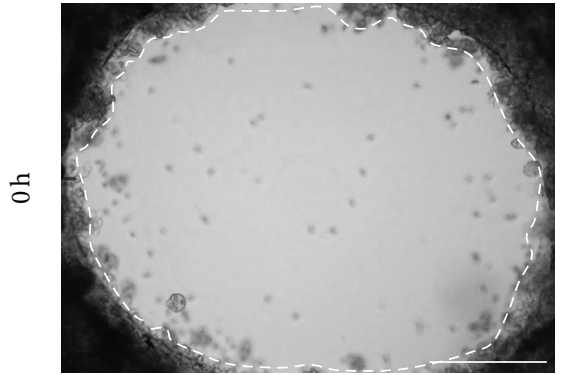

(a)

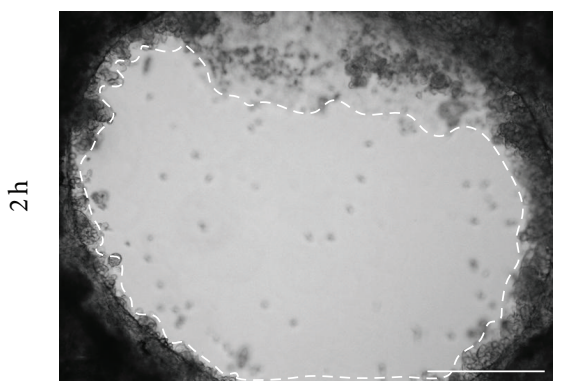

(d)

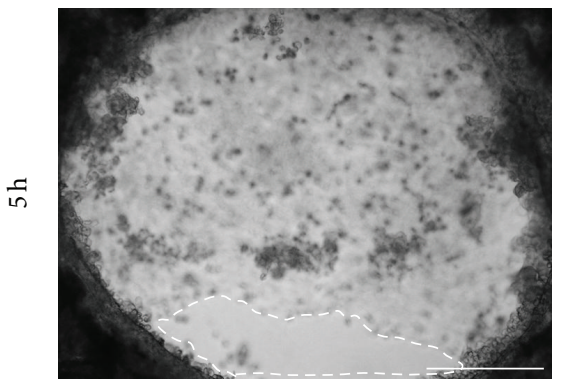

(g)

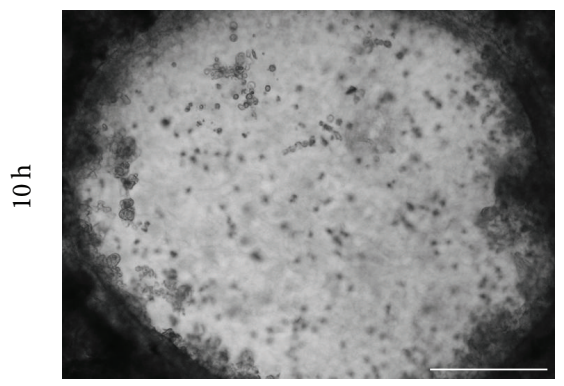

(j)
$12 \mathrm{kPa}$

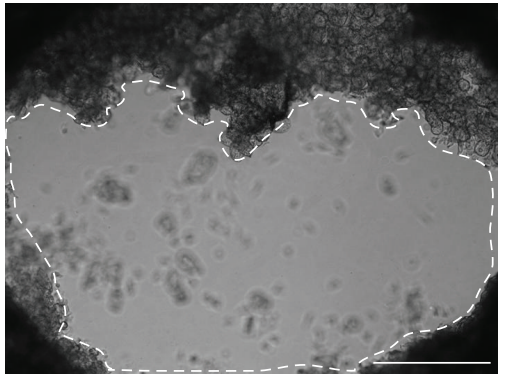

(b)

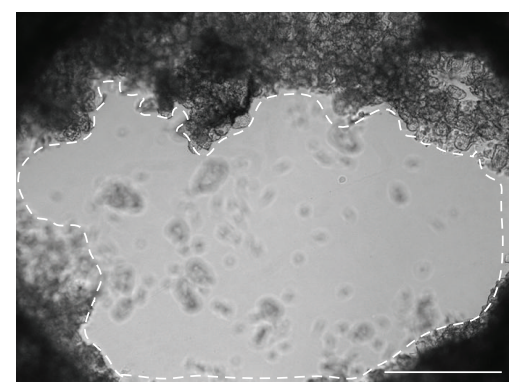

(e)

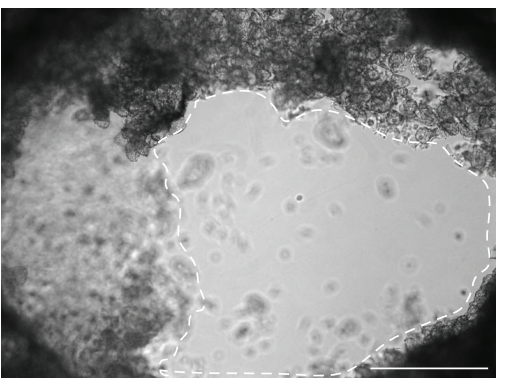

(h)

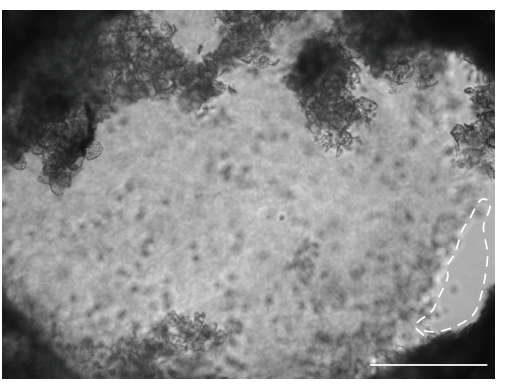

(k)
$50 \mathrm{kPa}$

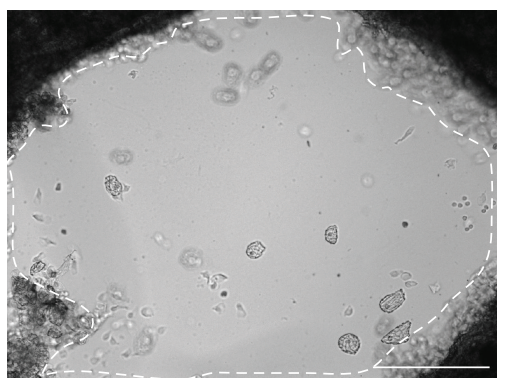

(c)

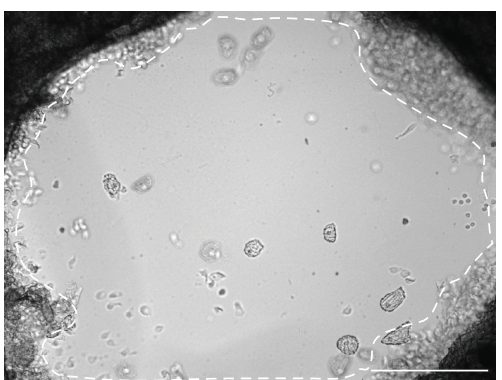

(f)

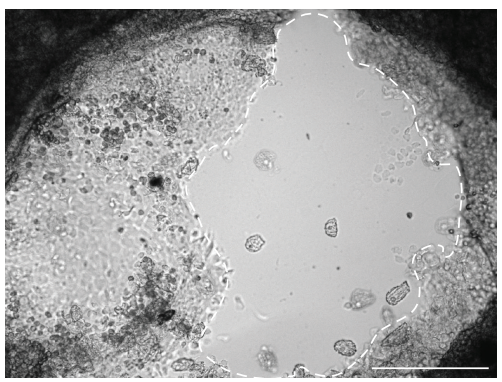

(i)

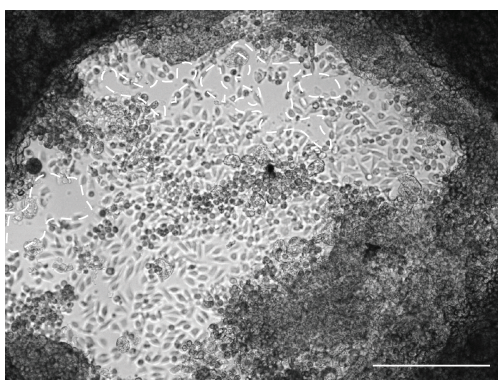

(1)

FIGURE 1: In vitro culture of axolotl skin explants on substrates with various degrees of stiffness. All skin explants initially exhibited 2 mm punched holes; images of reepithelialization were recorded every $15 \mathrm{~min}$. The unrecovered area is circled by a dashed line. Three degrees of substrate stiffness $(2,12$, and $50 \mathrm{kPa})$ were investigated, respectively, from (a) to (c), (d) to (f), (g) to (i), and (j) to (l). From 0 to $2 \mathrm{~h}$, most of the area was still uncovered in (a) to (c) and (d) to (f). After $2 \mathrm{~h}$, the reepithelialization rate increased and more area was covered in ( $\mathrm{g}$ ) to (i); healing was complete within $10 \mathrm{~h}$ in (j) to (l); scale bars: $500 \mu \mathrm{m}$.

$[16,17,31]$. However, it is a challenging task to track the whole wound healing process in adult axolotls, and there was no suitable cell line for further investigation. Developing an in vitro culture system was able to bridge the gap between the animal experiment and cell culture approach. In this study, we cultured skin explants from axolotl hind limbs, controlling parameters, including substrate stiffness and extracellular matrix proteins. According to our results, the wounded skins with a $2 \mathrm{~mm}$ punch recovered in $12 \mathrm{~h}$ with reepithelialization rates of 0.18 to $0.4 \mathrm{~mm}^{2} / \mathrm{h}$. These results 


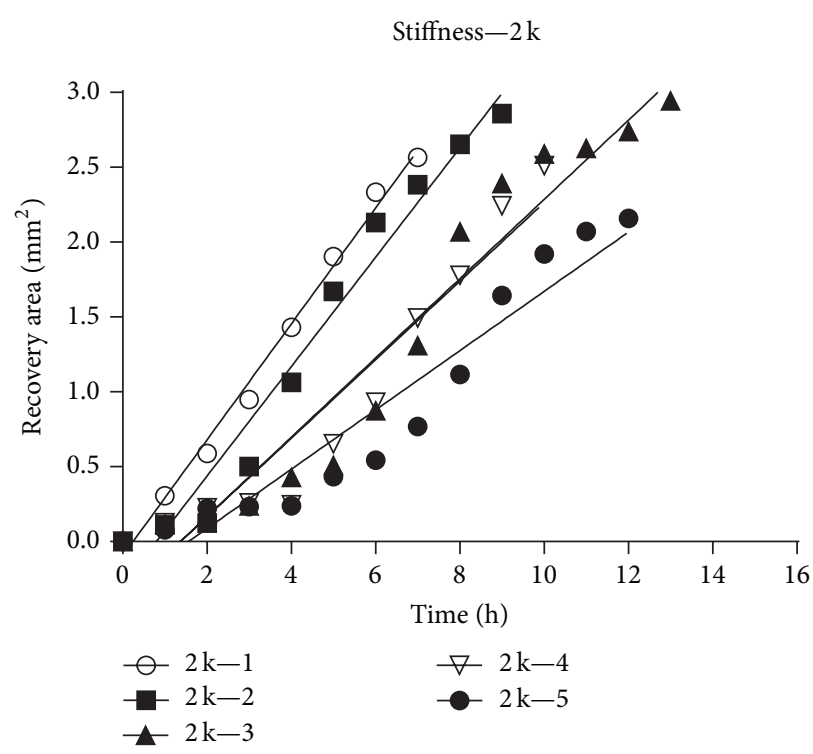

(a)

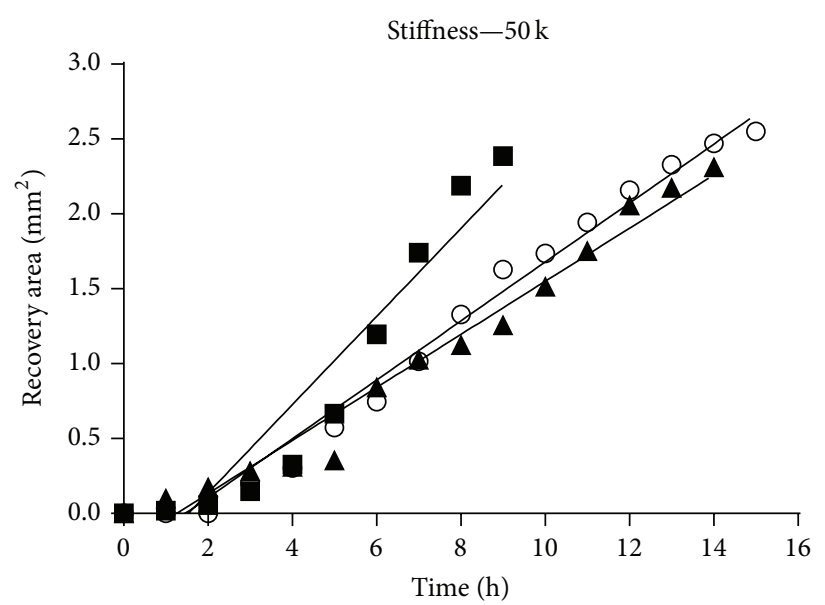

○ $50 \mathrm{k}-1$
$-50 \mathrm{k}-2$
$-50 \mathrm{k}-3$

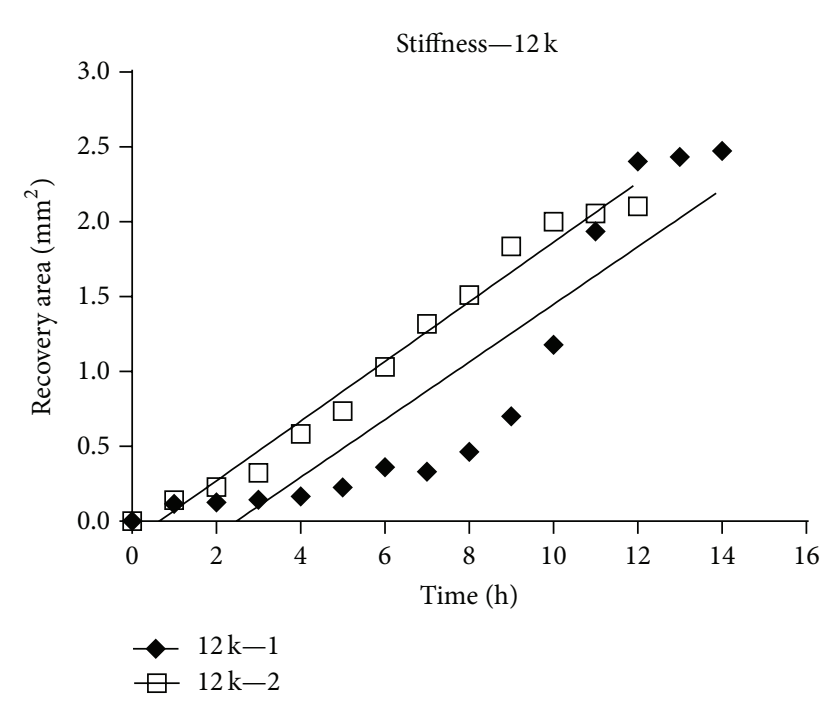

(b)

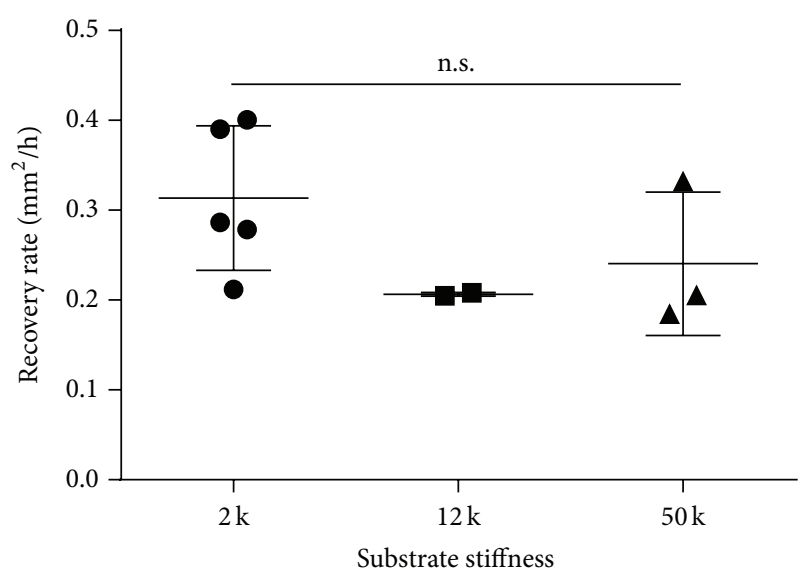

- $2 \mathrm{k}$
- $12 \mathrm{k}$
A $50 \mathrm{k}$

(c)

(d)

FIGURE 2: Quantitative analysis of the skin-wound closure rate in substrates with various degrees of stiffness. Sequential images of the complete reepithelialization of skin explants were recorded for $15 \mathrm{~h}$. Levels of skin recovery are shown for three degrees of substrate stiffness: five of six, two of six, and three of six skin explants in (a), (b), and (c), respectively, completely healed within 15 h. The keratinocytes migrated little during $0-2 \mathrm{~h}$, and the average wound closure rate was between 0.18 and $0.4 \mathrm{~mm}^{2} / \mathrm{h}$. The average migration rate was not significantly different between these treatments by unpaired $t$-test $(\mathrm{d})$.

are comparable to those of two recent in vivo studies: recovery of skin with a $1.5 \mathrm{~mm}$ punch required $<8 \mathrm{~h}[2]$; recovery of skin with a $4 \mathrm{~mm}$ punch required $<24 \mathrm{~h}$ [1]. In addition, in an in vitro study, recovery of skin with a $2 \mathrm{~mm}$ punch required $<11 \mathrm{~h}$ [27], suggesting that the in vitro approach simulated the wound healing process in axolotls. Most of the skin explants exhibited a constant rate of healing in the wound area (Figure 2); few explants exhibited accelerating reepithelialization during the wound recovery process (Figure 2(a), filled circle; Figure 2(b), filled diamond). This abrupt change in the migration rate suggests that there is an interaction between the collective epithelial cells and the surrounding microenvironment. The adherent collective cells have been shown to exert a strong traction force on the anchor site of the matrix [32-34] and surrounding cells [35-38]; the stress response from the matrix might alter the cytoskeleton arrangement and network in the cell. This synergistic cooperation between the wound-healing epithelial cells and their environment is believed to play a role in the rapid recovery of the wound area in axolotls. Future experiments will be needed to identify the genes during various healing stages and determine molecules 


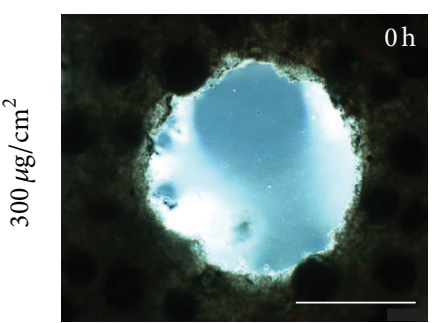

(a)

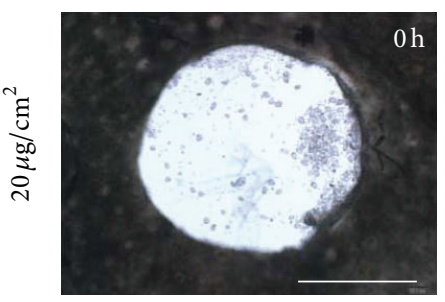

(e)

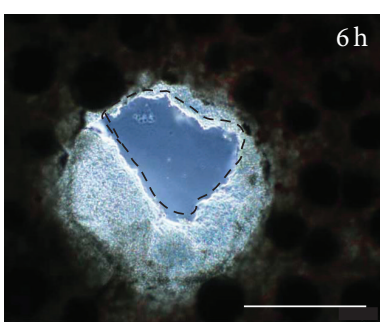

(b)

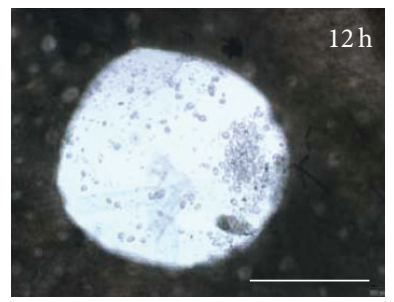

(f)

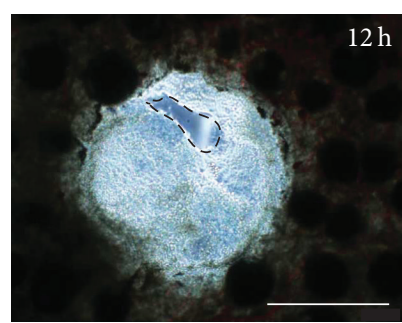

(c)

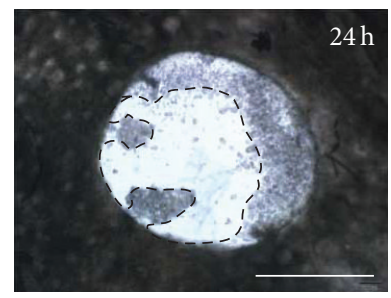

(g)

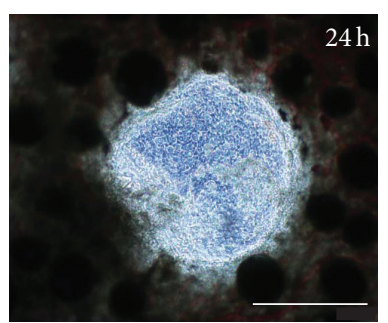

(d)

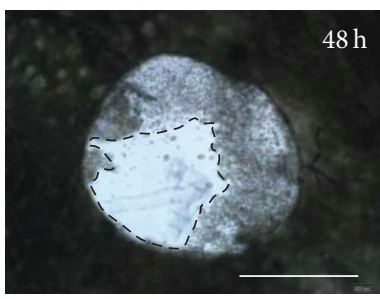

(h)

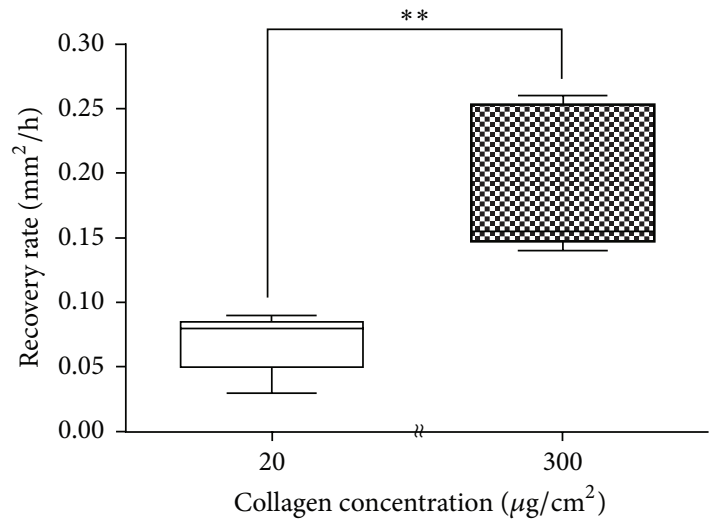

(i)

FIGURE 3: In vitro culture of axolotl skin explants on a polystyrene plate. Skin explants with $2 \mathrm{~mm}$ punch holes were cultured on $300 \mu \mathrm{g} / \mathrm{cm}^{2}$, (a) to (d), and $20 \mu \mathrm{g} / \mathrm{cm}^{2}$, (e) to (h) collagen-coated petri dishes. Images of the wound closure were obtained within $24 \mathrm{~h}$ (a) to (d) and $48 \mathrm{~h}$ (e) to (h). After culturing for $48 \mathrm{~h}$, the wounded areas remained unable to recover completely on $20 \mu \mathrm{g} / \mathrm{cm}^{2}$ collagen-coated polystyrene plate (h, dashed line). Cultured wound epithelium showed significant difference of average migration rate after $6 \mathrm{~h}$ incubation by unpaired $t$-test (i). Sample sizes for each condition were as follows: $20 \mu \mathrm{g} / \mathrm{cm}^{2}$ for $6 \mathrm{~h}$ culture: $N=5 ; 300 \mu \mathrm{g} / \mathrm{cm}^{2}$ for $6 \mathrm{~h}$ culture: $N=5 .{ }^{* *} P=0.0018$. Scale bars: $1000 \mu \mathrm{m}$.

that might stimulate or activate the onset of keratinocyte migration in the early phase of axolotl wound healing.

In the softest environment in our experiments, none of the skin explants $(n=6)$ with a substrate stiffness of $0.2 \mathrm{kPa}$ and collagen coat recovered completely; however, most of the wounded skins healed completely when substrate stiffness exceeded $2 \mathrm{kPa}$ (Table 1). We did not observe the recovery of the wounded skin cultured in a tenascin$(n=6)$ or laminin-coated $(n=6)$ environment with various degrees of substrate stiffness and noted only a partial recovery in the fibronectin- $(n=2$ in 6,33\%) coated environment (Table 1). However, the in vitro culture of the primary newt myoblasts exhibited a higher migration rate and a preferential muscle fragmentation in the tenascinrich environment with a substrate stiffness of 2 and $15 \mathrm{kPa}$ [23]. In vertebrates, mammalian epithelial cells exhibit an increase in migration speed with increasing stiffness [25]. To investigate skin recovery in a harder environment, we cultured wounded skins on a polystyrene collagen-coated plate featuring a $1 \mathrm{GPa}$ stiffness. After $48 \mathrm{~h}$ of culturing, recovery was not fully completed, suggesting that a harder material or environment impedes epithelial cell migration in axolotls (Figure 3). The sensitivity of cells to biophysical cues was also observed in early stage of mouse embryo cultures [24]. The percent development, hatching frequency, and cell number in the mouse-embryo development were affected when culturing was performed with a substrate stiffness of $1 \mathrm{kPa}$ and $1 \mathrm{GPa}$. In sum, in different species and cell types, substrate stiffness and environments where cells contact with might affect the physical or morphology behavior of the cells. This suggests that creating a microenvironment that mimics in vivo conditions is feasible when appropriate combinations of substrate stiffness and extracellular matrices are used.

Adult mammals are incapable of healing in full-thickness skin wound damage, whereas fetal mammals can recover from similar types of wounds through scar-free healing [7]. 


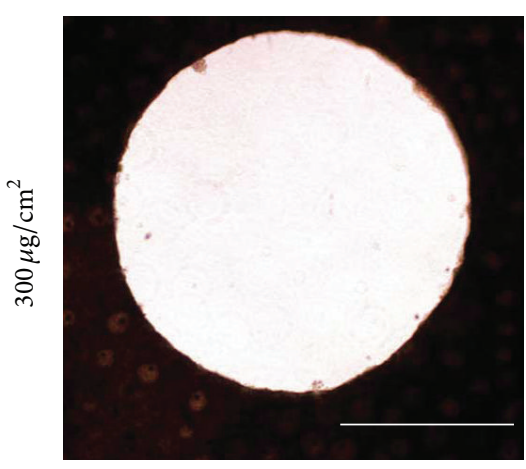

(a)

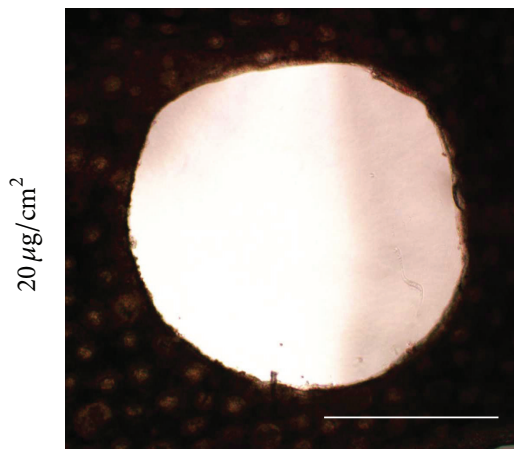

(d)

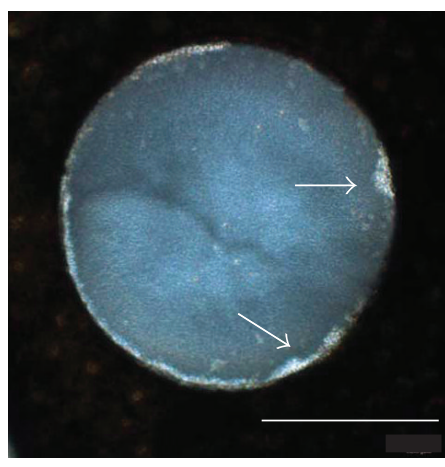

(b)

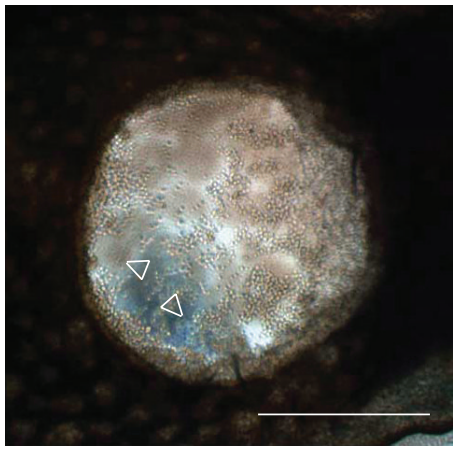

(e)

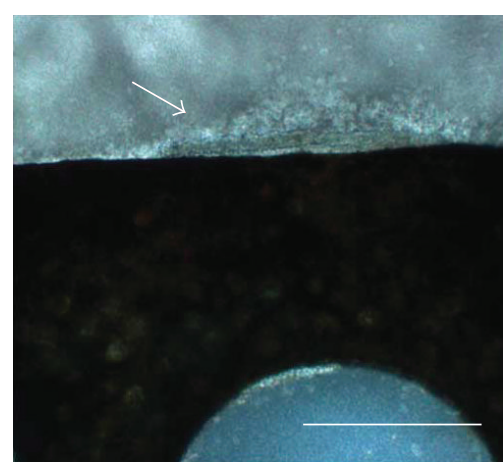

(c)

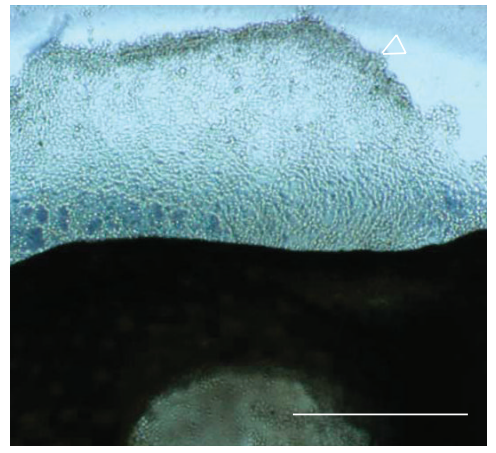

(f)

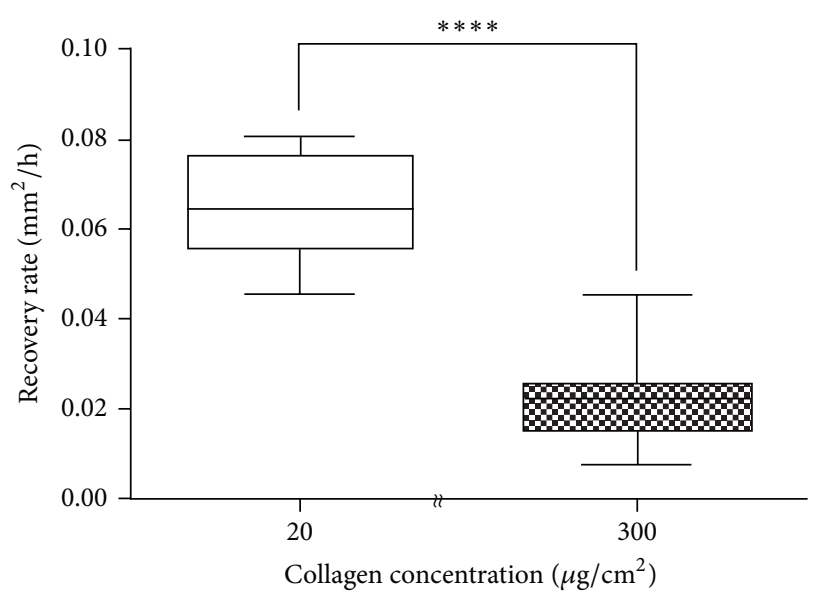

(g)

FIGURE 4: In vitro culture of metamorphic axolotl skin explants on polystyrene plate. Skin explants with 2 mm holes were cultured on $300 \mu \mathrm{g} / \mathrm{cm}^{2}$, (a) to (c), and $20 \mu \mathrm{g} / \mathrm{cm}^{2}$, (d) to (f), collagen-coated plate. After $24 \mathrm{~h}$ of culturing, the keratinocytes migrated little, neither from the inner punched holes (b, arrows) nor from the outer edge of the skin explants (c, arrow) on the $300 \mu \mathrm{g} / \mathrm{cm}^{2}$ collagen-coated petri dish. By contrast, on the $20 \mu \mathrm{g} / \mathrm{cm}^{2}$ collagen-coated petri dish, the keratinocytes migrated further, both inner and outer from the skin explants (e and $\mathrm{f}$, hollow arrow heads). Wound epithelium recovery showed significant difference of average migration rate after $24 \mathrm{~h}$ incubation by unpaired $t$-test (g). Sample sizes for each condition were as follows: $20 \mu \mathrm{g} / \mathrm{cm}^{2}: N=6 ; 300 \mu \mathrm{g} / \mathrm{cm}^{2}: N=9$. ${ }^{* * * *} P<0.0001$. Scale bars: $1000 \mu \mathrm{m}$.

This phenomenon has also been observed in amphibians and anurans undergoing metamorphosis heal wounds through scar formation [39]. However, tadpoles and pre- and postmetamorphic urodeles exhibit limitations such as embryonic development [40-42], body size [43-46], and aging [47, 48] for further wound healing investigation. Compared with tadpoles and urodeles, axolotls feature an ideal system for investigating wound healing because metamorphosis can be induced experimentally, and the age-associated factors can be controlled. In this paper, we describe the recovery of fullthickness skin wounds on axolotl limbs using an in vitro culture approach in paedomorphs (Figure 1) and in metamorphs (Figure 4); the wounded skin from metamorphic axolotls exhibited delayed reepithelialization within $24 \mathrm{~h}$. This is similar to the in vivo wound healing of metamorphic axolotls observed by Seifert et al. in 2012 [1]. In addition, 
TABLE 1: Effect of substrate stiffness and extracellular matrix proteins on wound closure in skin explants culture.

\begin{tabular}{|c|c|c|c|c|c|}
\hline & Stiffness $(\mathrm{kPa})$ & $\begin{array}{c}\text { Number of skin } \\
\text { explants }\end{array}$ & $\begin{array}{c}\text { Complete } \\
\text { wound closure }\end{array}$ & $\begin{array}{c}\text { Partial wound } \\
\text { closure }\end{array}$ & $\begin{array}{c}\text { No wound } \\
\text { closure }\end{array}$ \\
\hline \multirow{4}{*}{$\begin{array}{l}\text { Collagen } \\
\left(20 \mu \mathrm{g} / \mathrm{cm}^{2}\right)\end{array}$} & 0.2 & 6 & 0 & 4 & 2 \\
\hline & 2 & 6 & 5 & 1 & 0 \\
\hline & 12 & 6 & 1 & 5 & 0 \\
\hline & 50 & 6 & 2 & 4 & 0 \\
\hline \multirow{4}{*}{$\begin{array}{l}\text { Tenascin } \\
\left(2 \mu \mathrm{g} / \mathrm{cm}^{2}\right)\end{array}$} & 0.2 & 6 & 0 & 0 & 6 \\
\hline & 2 & 6 & 0 & 0 & 6 \\
\hline & 12 & 6 & 0 & 0 & 6 \\
\hline & 50 & 6 & 0 & 0 & 6 \\
\hline \multirow{4}{*}{$\begin{array}{l}\text { Fibronectin } \\
\left(2 \mu \mathrm{g} / \mathrm{cm}^{2}\right)\end{array}$} & 0.2 & 6 & 0 & 0 & 6 \\
\hline & 2 & 6 & 0 & 0 & 6 \\
\hline & 12 & 6 & 0 & 0 & 6 \\
\hline & 50 & 6 & 0 & 2 & 4 \\
\hline \multirow{4}{*}{$\begin{array}{l}\text { Laminin } \\
\left(2 \mu \mathrm{g} / \mathrm{cm}^{2}\right)\end{array}$} & 0.2 & 6 & 0 & 0 & 6 \\
\hline & 2 & 6 & 0 & 0 & 6 \\
\hline & 12 & 6 & 0 & 0 & 6 \\
\hline & 50 & 6 & 0 & 0 & 6 \\
\hline
\end{tabular}

${ }^{*}$ Skin explants were sliced into $4 \times 4 \mathrm{~mm}^{2}$ and punched $2 \mathrm{~mm}$ hole in the center.

* Wound closure was determined and recorded after $15 \mathrm{~h}$ culture.

we cultured the metamorphic wounded skin in a hard environment and discovered that the reepithelialization rate substantially increased (Figure $4(\mathrm{~g})$ ). We hypothesized that the change in epigenetic regulation might be determined by the axolotl metamorphosis and result in various healing processes, affecting scar formation and the specific reaction to the microenvironment of cells. In mammals, the epigenetic regulation exerts a strong influence on the phenotype of myofibroblast, which is involved in fibrogenesis and scar formation [49]. Furthermore, the interaction between DNA methylation and MeCP2 is crucial for the differentiation and fibrosis of myofibroblast in the liver and lungs [50, 51]. Therefore, comparing the epigenetic profiling during the healing process in paedomorphic and metamorphic axolotls might yield insights into the rapid reepithelialization and scar-free wound healing of axolotls. Furthermore, investigating controllable factors such as substrate stiffness and extracellular matrix proteins shown in this study was able to alter reactions of cells in in vivo environment.

Our findings reveal that the reepithelialization during the wound healing process in axolotls can be mimicked by using an in vitro approach and the cell behavior are regulated by controlled extracellular matrix proteins and substrate stiffness. These findings indicate that integrated cues from the microenvironment affect the cell reaction, for example, accelerating or impeding the cell migration. Furthermore, using this approach, we not only successfully repeated the in vitro wound healing process developed by Ferris et al. (2010) [27] in our system but also demonstrated the mechanical and biochemical properties regulating the plasticity of epithelial cells.

\section{Conflict of Interests}

The authors have declared that no conflict of interests exists.

\section{Acknowledgments}

This study is supported by a grant from the Ministry of Science and Technology (MOST 102-2314-B-002-127-MY3), Taiwan. The authors thank Chin-Hsiung Tsai for biomaterial information, Hua-Man Hsu for real-time microscopy analysis, Professor Jaw-Lin Wang for detection of in vivo wound healing process in axolotls, and National Taiwan University for technical and facility support.

\section{References}

[1] A. W. Seifert, J. Monaghan, R. Voss, and M. Maden, "Skin regeneration in adult axolotls: a blueprint for scar-free healing in vertebrates," PLoS ONE, vol. 7, no. 4, Article ID e32875, 2012.

[2] M. Levesque, É. Villiard, and S. Roy, "Skin wound healing in axolotls: a scarless process," Journal of Experimental Zoology Part B: Molecular and Developmental Evolution, vol. 314, no. 8, pp. 684-697, 2010.

[3] J. P. Brockes, "Amphibian limb regeneration: rebuilding a complex structure," Science, vol. 276, no. 5309, pp. 81-87, 1997.

[4] M. Han, X. Yang, G. Taylor, C. A. Burdsal, R. A. Anderson, and K. Muneoka, "Limb regeneration in higher vertebrates: developing a roadmap," Anatomical Record, Part B New Anatomist, vol. 287, no. 1, pp. 14-24, 2005.

[5] H. Wallace, Vertebrate Limb Regeneration, John Wiley \& Sons, Chichester, UK, 1981. 
[6] J. R. Armstrong and M. W. J. Ferguson, "Ontogeny of the skin and the transition from scar-free to scarring phenotype during wound healing in the pouch young of a marsupial, Monodelphis domestica," Developmental Biology, vol. 169, no. 1, pp. 242-260, 1995.

[7] K. M. Bullard, M. T. Longaker, and H. P. Lorenz, "Fetal wound healing: current biology," World Journal of Surgery, vol. 27, no. 1, pp. 54-61, 2003.

[8] C. M. Dang, S. R. Beanes, H. Lee, X. Zhang, C. Soo, and K. Ting, "Scarless fetal wounds are associated with an increased matrix metalloproteinase-to-tissue-derived inhibitor of metalloproteinase ratio," Plastic and Reconstructive Surgery, vol. 111, no. 7, pp. 2273-2285, 2003.

[9] R. Y. Lin, K. M. Sullivan, P. A. Argenta, M. Meuli, H. P. Lorenz, and N. S. Adzick, "Exogenous transforming growth-factor-beta amplifies its own expression and induces scar formation in a model of human fetal skin repair," Annals of Surgery, vol. 222, no. 2, pp. 146-154, 1995.

[10] K. Muneoka and S. V. Bryant, "Evidence that patterning mechanisms in developing and regenerating limbs are the same," Nature, vol. 298, no. 5872, pp. 369-371, 1982.

[11] L. A. Repesh and J. C. Oberpriller, "Scanning electron microscopy of epidermal cell migration in wound healing during limb regeneration in the adult newt, Notophthalmus viridescens," American Journal of Anatomy, vol. 151, no. 4, pp. 539-555, 1978.

[12] D. J. Donaldson, J. T. Mahan, H. Yang, and K. M. Yamada, "Integrin and phosphotyrosine expression in normal and migrating newt keratinocytes," Anatomical Record, vol. 241, no. 1, pp. 49$58,1995$.

[13] T. Endo, S. V. Bryant, and D. M. Gardiner, "A stepwise model system for limb regeneration," Developmental Biology, vol. 270, no. 1, pp. 135-145, 2004.

[14] M. R. J. Carlson, S. V. Bryant, and D. M. Gardiner, "Expression of Msx-2 during development, regeneration, and wound healing in axolotl limbs," The Journal of Experimental Zoology, vol. 282, no. 6, pp. 715-723, 1998.

[15] M. Lévesque, S. Gatien, K. Finnson et al., "Transforming growth factor: beta signaling is essential for limb regeneration in axolotls," PLoS ONE, vol. 2, no. 11, Article ID e1227, 2007.

[16] G. Odland and R. Ross, "Human wound repair. I. Epidermal regeneration," The Journal of Cell Biology, vol. 39, no. 1, pp. 135151, 1968.

[17] C. B. Viziam, A. G. Matoltsy, and H. Mescon, "Epithelialization of small wounds," The Journal of Investigative Dermatology, vol. 43, pp. 499-507, 1964.

[18] R. B. Page and S. R. Voss, "Induction of metamorphosis in axolotls (Ambystoma mexicanum)," Cold Spring Harbor Protocols, vol. 2009, no. 8, Article ID pdb.prot5268, 2009.

[19] K. Crawford and D. M. Vincenti, "Retinoic acid and thyroid hormone may function through similar and competitive pathways in regenerating axolotls," Journal of Experimental Zoology, vol. 282, no. 6, pp. 724-738, 1998.

[20] K. R. Legate, S. A. Wickström, and R. Fässler, "Genetic and cell biological analysis of integrin outside-in signaling," Genes \& Development, vol. 23, no. 4, pp. 397-418, 2009.

[21] G. S. Schultz and A. Wysocki, "Interactions between extracellular matrix and growth factors in wound healing," Wound Repair and Regeneration, vol. 17, no. 2, pp. 153-162, 2009.

[22] S. Nemir and J. L. West, "Synthetic materials in the study of cell response to substrate rigidity," Annals of Biomedical Engineering, vol. 38, no. 1, pp. 2-20, 2010.
[23] S. Calve and H.-G. Simon, "Biochemical and mechanical environment cooperatively regulate skeletal muscle regeneration," The FASEB Journal, vol. 26, no. 6, pp. 2538-2545, 2012.

[24] K. S. Kolahi, A. Donjacour, X. Liu et al., "Effect of substrate stiffness on early mouse embryo development," PLoS ONE, vol. 7, no. 7, Article ID e41717, 2012.

[25] M. R. Ng, A. Besser, G. Danuser, and J. S. Brugge, "Substrate stiffness regulates cadherin-dependent collective migration through myosin-II contractility," Journal of Cell Biology, vol. 199, no. 3, pp. 545-563, 2012.

[26] C.-M. Lo, H.-B. Wang, M. Dembo, and Y.-L. Wang, "Cell movement is guided by the rigidity of the substrate," Biophysical Journal, vol. 79, no. 1, pp. 144-152, 2000.

[27] D. R. Ferris, A. Satoh, B. Mandefro, G. M. Cummings, D. M. Gardiner, and E. L. Rugg, "Ex vivo generation of a functional and regenerative wound epithelium from axolotl (Ambystoma mexicanum) skin," Development Growth and Differentiation, vol. 52, no. 8, pp. 715-724, 2010.

[28] V. F. Achterberg, L. Buscemi, H. Diekmann et al., "The nanoscale mechanical properties of the extracellular matrix regulate dermal fibroblast function," Journal of Investigative Dermatology, vol. 134, no. 7, pp. 1862-1872, 2014.

[29] M. W. J. Ferguson and S. O'Kane, "Scar-free healing: from embryonic mechanism to adult therapeutic intervention," Philosophical Transactions of the Royal Society B: Biological Sciences, vol. 359, no. 1445, pp. 839-850, 2004.

[30] P. Martin, "Wound healing_Aiming for perfect skin regeneration," Science, vol. 276, no. 5309, pp. 75-81, 1997.

[31] L. Repesh and J. C. Oberpriller, "Ultrastructural studies on migrating epidermal cells during the wound healing stage of regeneration in the adult newt, Notophthalmus viridescens," American Journal of Anatomy, vol. 159, no. 2, pp. 187-208, 1980.

[32] S. Munevar, Y. L. Wang, and M. Dembo, "Traction force microscopy of migrating normal and $\mathrm{H}$-ras transformed 3T3 fibroblasts," Biophysical Journal, vol. 80, no. 4, pp. 1744-1757, 2001.

[33] J. L. Tan, J. Tien, D. M. Pirone, D. S. Gray, K. Bhadriraju, and C. S. Chen, "Cells lying on a bed of microneedles: an approach to isolate mechanical force," Proceedings of the National Academy of Sciences of the United States of America, vol. 100, no. 4, pp. 1484-1489, 2003.

[34] N. Q. Balaban, U. S. Schwarz, D. Riveline et al., "Force and focal adhesion assembly: a close relationship studied using elastic micropatterned substrates," Nature Cell Biology, vol. 3, no. 5, pp. 466-472, 2001.

[35] Y. S. Chu, W. A. Thomas, O. Eder et al., "Force measurements in E-cadherin-mediated cell doublets reveal rapid adhesion strengthened by actin cytoskeleton remodeling through Rac and Cdc42," Journal of Cell Biology, vol. 167, no. 6, pp. 1183-1194, 2004.

[36] A. Bershadsky, M. Kozlov, and B. Geiger, "Adhesion-mediated mechanosensitivity: a time to experiment, and a time to theorize," Current Opinion in Cell Biology, vol. 18, no. 5, pp. 472481, 2006.

[37] C. M. Nelson, R. P. Jean, J. L. Tan et al., "Emergent patterns of growth controlled by multicellular form and mechanics," Proceedings of the National Academy of Sciences of the United States of America, vol. 102, no. 33, pp. 11594-11599, 2005.

[38] A. Ganz, M. Lambert, A. Saez et al., "Traction forces exerted through N-cadherin contacts," Biology of the Cell, vol. 98, no. 12, pp. 721-730, 2006. 
[39] I. V. Yannas, J. Colt, and Y. C. Wai, "Wound contraction and scar synthesis during development of the amphibian Rana catesbeiana," Wound Repair and Regeneration, vol. 4, no. 1, pp. 29-39, 1996.

[40] R. G. Korneluk and R. A. Liversage, "Tissue regeneration in the amputated forelimb of Xenopus laevis froglets," Canadian Journal of Zoology, vol. 62, no. 12, pp. 2383-2391, 1984.

[41] K. Muneoka, G. Holler-Dinsmore, and S. V. Bryant, "Intrinsic control of regenerative loss in Xenopus laevis limbs," Journal of Experimental Zoology, vol. 240, no. 1, pp. 47-54, 1986.

[42] S. R. Scadding, "Phylogenic distribution of limb regeneration capacity in adult Amphibia," Journal of Experimental Zoology, vol. 202, no. 1, pp. 57-67, 1977.

[43] M. Maden, "Blastemal kinetics and pattern formation during amphibian limb regeneration," Journal of Embryology and Experimental Morphology, vol. 36, no. 3, pp. 561-574, 1976.

[44] W. H. Pritchett and J. N. Dent, "The role of size in the rate of limb regeneration in the adult newt," Growth, Development and Aging, vol. 36, no. 4, pp. 275-289, 1972.

[45] S. R. Scadding, "Limb regeneration in adult amphibia," Canadian Journal of Zoology, vol. 59, no. 1, pp. 34-46, 1981.

[46] A. W. Seifert, J. R. Monaghan, M. D. Smith et al., "The influence of fundamental traits on mechanisms controlling appendage regeneration," Biological Reviews, vol. 87, no. 2, pp. 330-345, 2012.

[47] A. W. Seifert and S. R. Voss, "Revisiting the relationship between regenerative ability and aging," $B M C$ Biology, vol. 11, article 2, 2013.

[48] G. Eguchi, Y. Eguchi, K. Nakamura, M. C. Yadav, J. L. Millán, and P. A. Tsonis, "Regenerative capacity in newts is not altered by repeated regeneration and ageing," Nature Communications, vol. 2, article 384, 2011.

[49] B. Hinz, S. H. Phan, V. J. Thannickal et al., "Recent developments in myofibroblast biology: paradigms for connective tissue remodeling," The American Journal of Pathology, vol. 180, no. 4, pp. 1340-1355, 2012.

[50] J. Mann, D. C. K. Chu, A. Maxwell et al., "MeCP2 controls an epigenetic pathway that promotes myofibroblast transdifferentiation and fibrosis," Gastroenterology, vol. 138, no. 2, pp. 705$714,2010$.

[51] B. Hu, M. Gharaee-Kermani, Z. Wu, and S. H. Phan, "Essential role of MeCP2 in the regulation of myofibroblast differentiation during pulmonary fibrosis," The American Journal of Pathology, vol. 178, no. 4, pp. 1500-1508, 2011. 


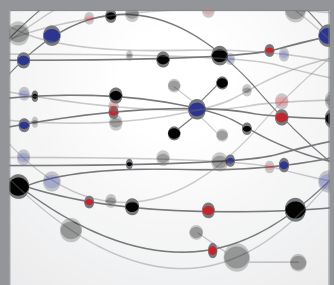

The Scientific World Journal
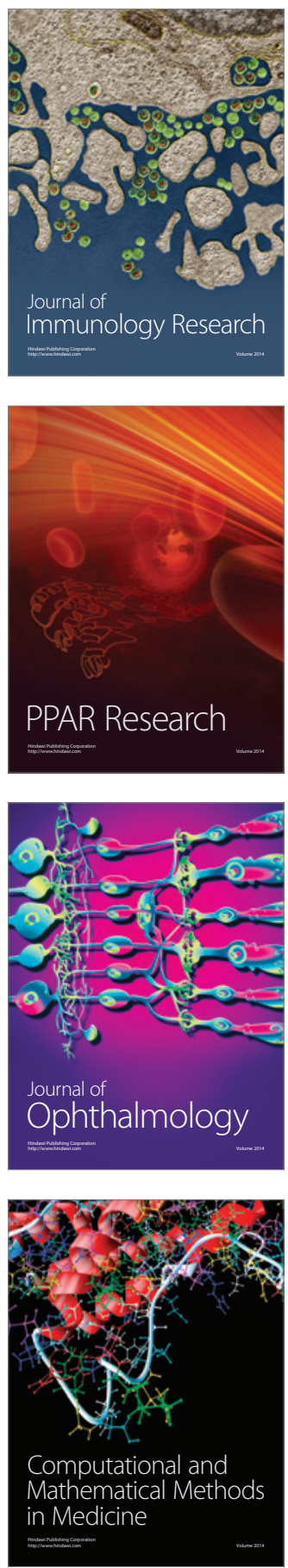

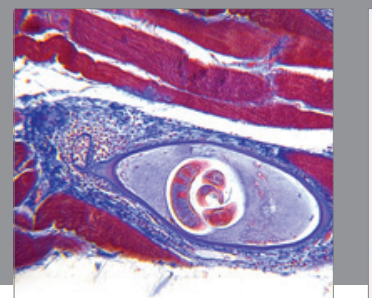

Gastroenterology

Research and Practice
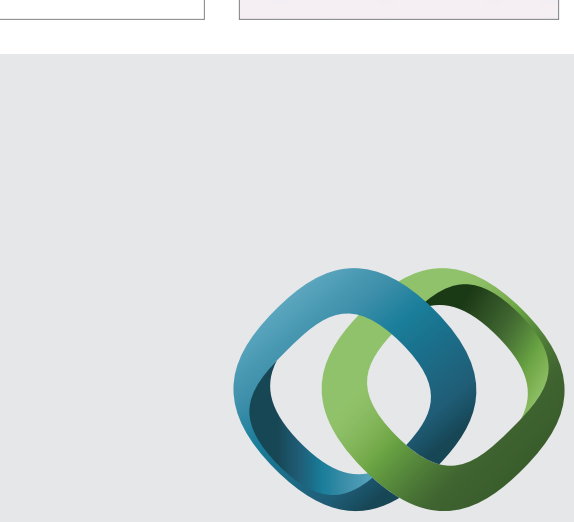

\section{Hindawi}

Submit your manuscripts at

http://www.hindawi.com
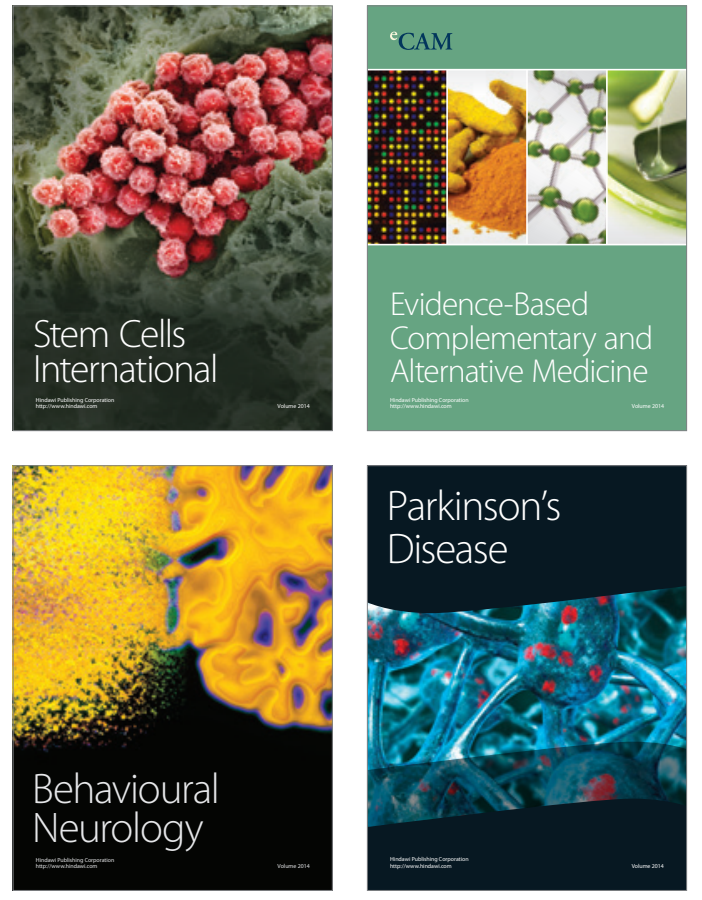
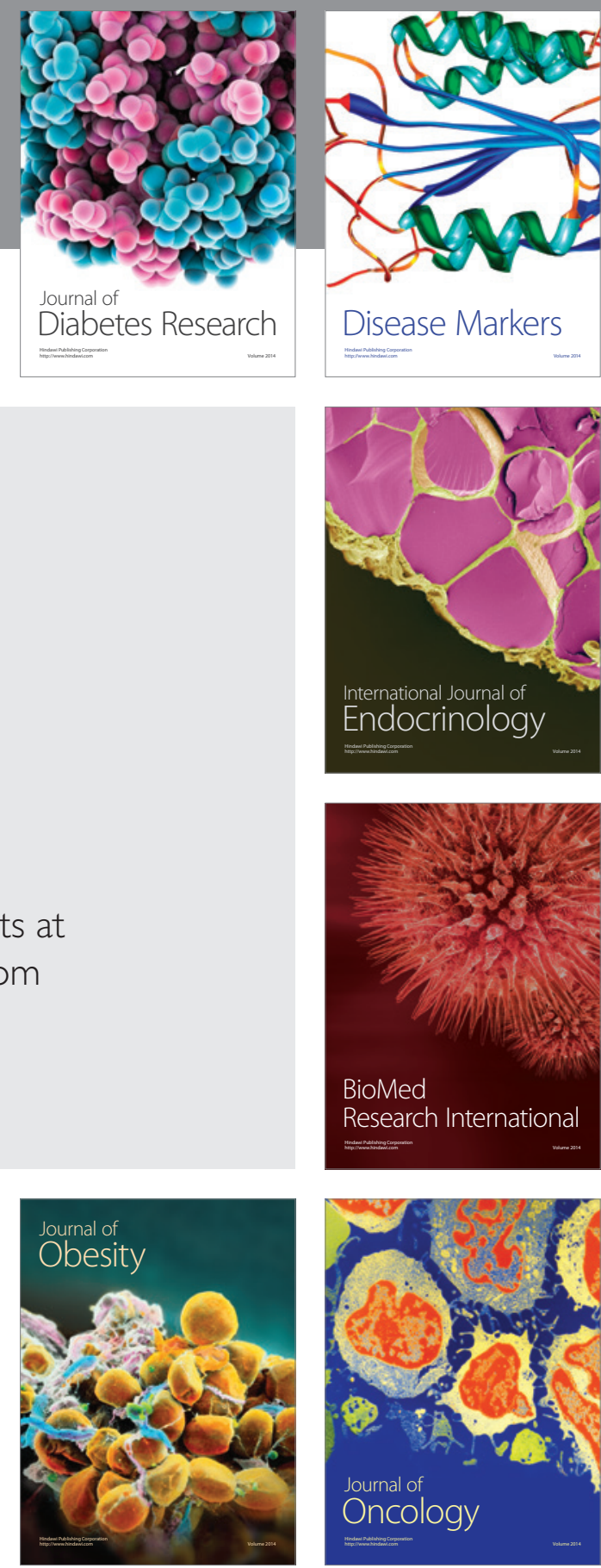

Disease Markers
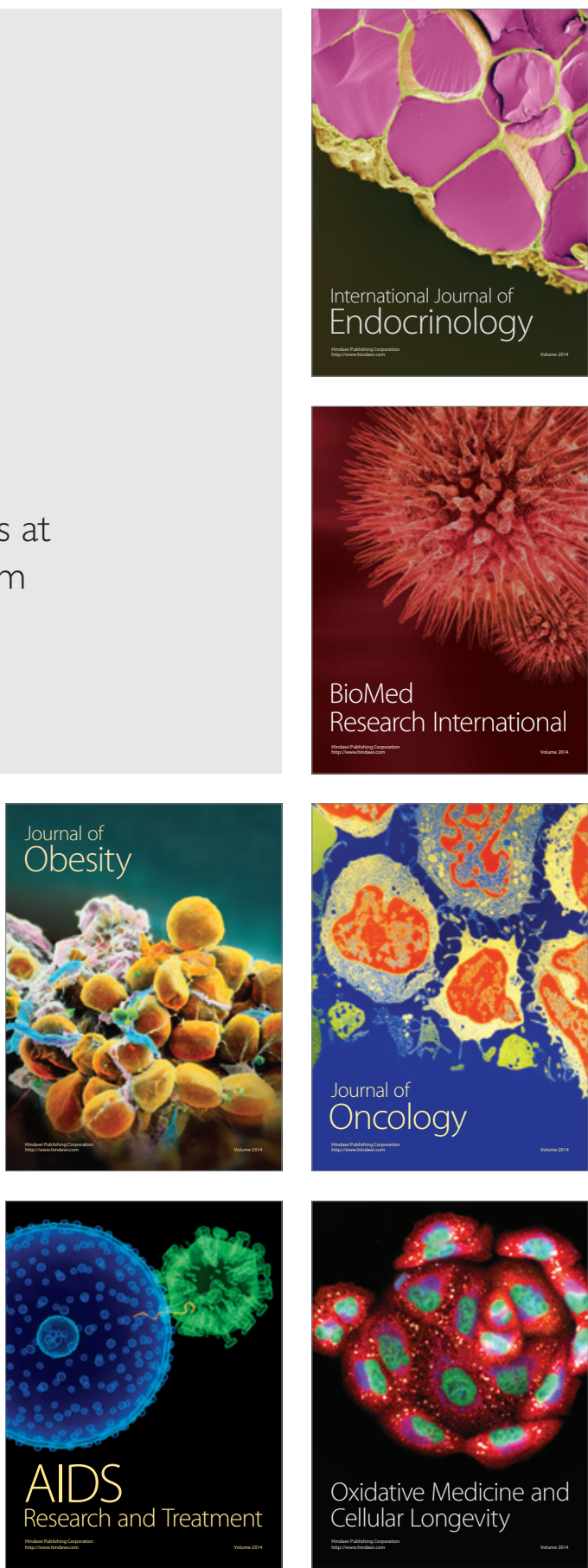